\title{
Solutions for present and future emerging pollutants in land and water resources management. Policy briefs summarizing scientific project results for decision makers
}

Werner Brack ${ }^{1,2^{*}}$

The European Water Framework Directive (WFD) [1] is one of the most ambitious regulations on water quality in the world. It is based on the understanding that "water is not a commercial product like any other but, rather, a heritage which must be protected, defended and treated as such". It has been shown that chemical pollution typically occurring in complex mixtures of regulated and non-regulated compounds compromise this heritage and pose a substantial risk to water quality and aquatic ecosystems [2-4]. The awareness of regulators, decision makers and practitioners in monitoring, assessment and management of chemical pollution is increasing that these findings jeopardize the ambitions of the WFD and European environmental policies that in general are striving for the goal of safeguarding a non-toxic environment [5]. Thus, in contrast to current practice, that limits the assessment of chemical contamination to a few Europewide priority substances complemented with some river basin-specific pollutants (RBSPs), there is strong evidence that chemical mixtures enhance the "likelihood that surface waters bodies ... fail to meet the environmental quality objectives" [1] and need to be considered in water quality monitoring and impact assessment.

The 5 years EU-funded project SOLUTIONS put major efforts into addressing this challenge by developing new concepts and tools for holistic and solutions-oriented monitoring, impact assessment and diagnosis, modeling and abatement of these complex mixtures [6-8]. On the one hand, the project had the ambition to provide innovative scientific results that help to better understand chemical mixtures as drivers of risks. On the other hand,

\footnotetext{
*Correspondence: werner.brack@ufz.de

${ }^{1}$ Helmholtz Centre for Environmental Research UFZ, Leipzig, Germany

Full list of author information is available at the end of the article
}

SOLUTIONS had a strong focus on developing solutions for minimizing risks in a close dialogue with stakeholders from the European Commission, European and national agencies, international river commissions, science-policy networks such as the NORMAN network on emerging pollutants, the water industry and others.

Based on extensive research, SOLUTIONS published a large number of high-quality scientific papers accessible via the website [7]. However, this may not be sufficient to make sure that the results can be used in political and regulatory processes such as in the review and practical implementation of the WFD. Thus, encouraged and supported by their stakeholders and, where appropriate, in collaboration with the partner projects MARS and GLOBAQUA, principle investigators from the SOLUTIONS consortium produced a series of policy briefs aiming to evaluate and translate the project results into recommendations on how to implement the new tools and which requirements need to be fulfilled to allow for such an implementation. This is illustrated by a compilation of selected achievements of the SOLUTIONS project supporting the recommendations with scientific findings from the project. While policy briefs have been already used in other projects as a channel of information for decision makers, the new format of policy briefs in Environmental Sciences Europe as a peer-reviewed open-access international journal is quite unique, with the ambition to complement purely scientific publications with efforts in science-policy interfacing. Probably reaching a much broader audience, these policy briefs address decision makers but are also meant to inspire and encourage applied researchers worldwide to bridge the gap between science and policy making by striving for science-based solutions for societal problems and by 
communicating scientific results in a format useful for stakeholders.

The policy briefs in this collection provide recommendations on the application of monitoring and assessment tools that help to address complex environmental mixtures and their likelihood to impact water quality. It is shown how analytical screening methods [9] together with component-based mixture assessment [10] may assist in getting a more holistic picture of contamination. These tools may help identify and prevent new hazards at an early stage, prioritize water bodies for abatement measures and control and reward the success of these measures. Recommendations for a European federated data infrastructure will help to compile and exchange the large amount of screening data for a cost and effort effective evaluation [11]. Complementary effect-based tools are recommended to monitor complex mixtures with the perspective of toxicity and risks [12]. This helps to minimize the risk of overlooking toxic agents even if they are unknown or biologically active below their analytical detection limit, and to directly consider mixture effects. In a multiple lines-of-evidence approach, in situ tests and field-derived species inventories are recommended to assess chemical pollution from an ecological perspective estimating the likelihood of impacts. In SOLUTIONS, it also became evident that monitoring can benefit a lot from complementary modeling approaches that help to fill data gaps and prioritize water bodies potentially at risk and chemicals that are produced, used and emitted in quantities that might pose a risk to aquatic ecosystems or humans [13]. The new approaches have been rigorously evaluated in large-scale European case studies including the Rhine and Danube catchments (Fig. 1) as well as several Spanish river basins and a number of additional field sites all over Europe and discussed with European and national agencies, international river commissions and many more important stakeholders. By integrating the SOLUTIONS monitoring and modeling tools with multiple stress investigations carried out in the MARS project [14], it could be shown that mixtures of chemicals are actually important drivers of impacts on the ecological status in European surface waters [15].

Prioritization of chemicals on different scales is required for the identification of EU-wide priority pollutants as well as of RBSPs in the Member States. While prioritization currently focuses on individual chemicals only, an advanced methodological framework for the integration of mixture risk assessment is proposed for prioritization procedures under the WFD [16]. To help stakeholders find their way through the extensive toolbox that is available to solve their problems in monitoring, modeling, impact assessment and management of chemical mixtures in the aquatic environment, SOLUTIONS provided a web tool called RiBaTox.

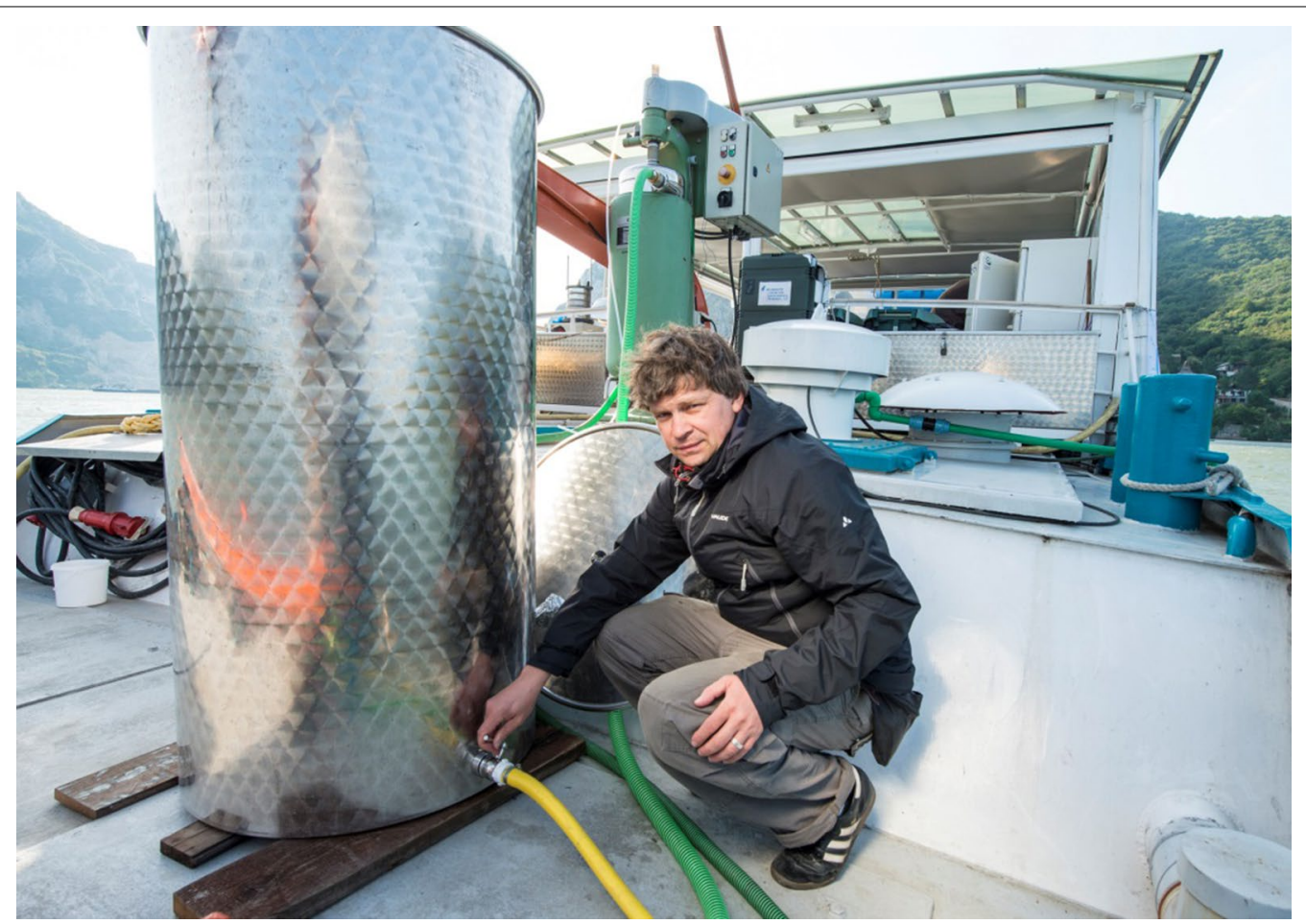

Fig. 1 SOLUTIONS sampling of water und suspended matter at Joint Danube Survey 3 
A policy brief gives guidance on how to use this tool that has been developed in close collaboration with stakeholders [17]. For an early-stage assessment and exploration of the solution space, that means the options to protect and restore water quality from chemical pollution, recommendations are given on the collation of technical abatement and non-technical solution strategies [18].

A better protection of water quality from mixture risks requires not only conceptual and technical innovation in monitoring and assessment but may also demand for changes to the WFD and a better coordination across the pieces of European chemical legislation [19] as well as an increase in coherence, cooperation and cross-compliance of chemicals and water regulations [20]. To finally meet the European policy goals for achieving a sustainable, nontoxic environment, European collaborative environmental research should be strengthened to mobilize the extensive European research capacities and competences required to address the enormous challenges we are facing to reduce modern society's footprints in general and toxic risks in particular [21]. This collection of policy briefs is meant to support this goal and facilitate decision makers to access scientific information required for the protection and restoration of European water resources as a basis for health and well-being of the European population and for high-quality ecosystems providing important services for this population.

\section{Acknowledgements}

This editorial has been prepared as an outcome of the SOLUTIONS project (European Union's Seventh Framework Programme for research, technological development and demonstration under Grant Agreement No. 603437).

\section{Authors' contributions}

WB is the sole author and was responsible for writing this editorial. The author read and approved the final manuscript.

\section{Availability of data and materials}

Not applicable.

\section{Competing interests}

The author declares no competing interests.

\section{Author details}

${ }^{1}$ Helmholtz Centre for Environmental Research UFZ, Leipzig, Germany. ${ }^{2}$ RWTH Aachen University, Aachen, Germany.

Received: 21 August 2019 Accepted: 27 August 2019

Published online: 30 September 2019

\section{References}

1. European Union (2000) Directive 2000/60/EC of the European Parliament and of the Council of 23 October 2000 establishing a framework for Community action in the field of water policy. Off J Eur Union L327:1-72

2. Malaj E et al (2014) Organic chemicals jeopardise freshwater ecosystems health on the continental scale. Proc Natl Acad Sci 111(26):9549-9554

3. Beketov MA et al (2013) Pesticides reduce regional biodiversity of stream invertebrates. Proc Natl Acad Sci USA 110(27):11039-11043

4. Moschet $\mathrm{C}$ et al (2014) How a complete pesticide screening changes the assessment of surface water quality. Environ Sci Technol 48(10):5423-5432
5. European Commission (2016) Living well, within the limits of our planet. 7th EAP_-the new general Union Environment Action Programme to 2020. https://ec.europa.eu/environment/efe/themes/economics-strat egy-and-information/here-2020-eu\%E2\%80\%99s-new-environmen t-action-programme_en

6. Brack W et al (2015) The SOLUTIONS project: challenges and responses for present and future emerging pollutants in land and water resources management. Sci Total Environ 503-504:22-31

7. SOLUTIONS (2015) SOLUTIONS for present and future emerging pollutants in land and water resources management. https://www.solut ions-project.eu/project/. Accessed 23 Aug 2019

8. Helmholtz Centre for Environmental Research-UFZ (2019) SOLUTIONS for a better water quality of European rivers. https://www.youtube.com/ watch?v=1Zu9fWi8eEY\&feature=youtu.be. Accessed 23 August 2019

9. BrackW et al (2019) High resolution mass spectrometry to complement monitoring and track emerging chemicals and pollution trends in European water resources. Environ Sci Eur. https://doi.org/10.1186/s1230 2-019-0230-0

10. Posthuma L et al (2019) Improved component-based methods for mixture risk assessment are key to characterize complex chemical pollution in surface waters. Environ Sci Eur. https://doi.org/10.1186/s1230 2-019-0246-5

11. Slobodnik J et al (2019) Establish data infrastructure to compile and exchange environmental screening data on a European scale. Environ Sci Eur. https://doi.org/10.1186/s12302-019-0237-6

12. Brack W et al (2019) Effect-based methods are key. The European Collaborative Project SOLUTIONS recommends integrating effect-based methods for diagnosis and monitoring of water quality. Environ Sci Eur 31:10

13. Van Gils J et al (2019) The European Collaborative Project SOLUTIONS developed models to provide diagnostic and prognostic capacity and fill data gaps for chemicals of emerging concern. Environ Sci Eur. https://doi. org/10.1186/s12302-019-0248-3

14. Hering $D$ et al (2015) Managing aquatic ecosystems and water resources under multiple stress - an introduction to the MARS project. Sci Total Environ 503:10-21

15. Posthuma $L$ et al (2019) Mixtures of chemicals are important drivers of impacts on ecological status in European surface waters. Environ Sci Eur. https://doi.org/10.1186/s12302-019-0247-4

16. Faust M et al (2019) Prioritisation of water pollutants: the EU Project SOLUTIONS proposes a methodological framework for the integration of mixture risk assessments into prioritisation procedures under the European Water Framework Directive. Environ Sci Eur. https://doi.org/10.1186/ s12302-019-0239-4

17. Kramer KJM et al (2019) The RiBaTox web tool: selecting methods to assess and manage the diverse problem of chemical pollution in surface waters. Environ Sci Eur. https://doi.org/10.1186/s12302-019-0244-7

18. Posthuma L et al (2019) Exploring the 'solution space' is key. SOLUTIONS recommends an early-stage assessment of options to protect and restore water quality regarding chemical pollution. Environ Sci Eur. https://doi. org/10.1186/s12302-019-0253-6

19. Kortenkamp A et al (2019) Mixture risks threaten water quality: the European Collaborative Project SOLUTIONS recommends changes to the WFD and better coordination across all pieces of European chemicals legislation to improve protection from exposure of the aquatic environment to multiple pollutants. Environ Sci Eur. https://doi.org/10.1186/ s12302-019-0245-6

20. Munthe J et al (2019) Increase coherence, cooperation and cross-compliance of regulations on chemicals and water quality. Environ Sci Eur. https ://doi.org/10.1186/s12302-019-0235-8

21. Brack W et al (2019) Strengthen the European collaborative environmental research to meet European policy goals for achieving a sustainable, non-toxic environment. Environ Sci Eur. https://doi.org/10.1186/s1230 2-019-0232-y

\section{Publisher's Note}

Springer Nature remains neutral with regard to jurisdictional claims in published maps and institutional affiliations. 